A. Zielinski ${ }^{1}$, S. Sobieszczyk ${ }^{2}$

Gdansk University of Technology, Faculty of Mechanical Engineering, ${ }^{1}$ Department of Materials and Welding Engineering, ${ }^{2}$ Department of Mechanical Engineering and Mechatronics, Narutowicza 11/12, 80-233 Gdańsk, Poland

\title{
NANOTECHNOLOGIES IN DEVELOPMENT OF STRUCTURAL MATERIALS AND BIOMATERIALS
}

\begin{abstract}
The nanometric materials and technologies resulted in nanostructures are reviewed. The examples of nanomaterials are shown. The typical nanotechnologies, including plastic deformation, mechanical attrition, controlled detonation, hot plasma jet synthesis, laser vaporisation, CVD and PVD, mechanical milling, annealing, ultrasonic irradiation, nanolithography, electrocrystallisation, electrospinning, sol-gel method, cryogenic laser-enhanced melting, and hydrogen-enhanced amorphisation, are presented. Typical applications in technics and medicine are given.
\end{abstract}

Key words: nanomaterials, nanotechnologies, physical methods, chemical methods, mechanical methods

\section{INTRODUCTION}

The structures composed of particles for which at least one dimension comprises between 1 and $100 \mathrm{~nm}$, are called nanomaterials [1]. The history of development of nanomaterials started at 1959 with an exciting lecture of Richard Feynman - the scientist engaged in construction of atomic bomb, teacher, raconteur, and musician entitled "There is a plenty of room at the bottom". However, it has been only an idea of creating any object by putting together single atoms or molecules. This idea has been followed by Eric Drexler, who thanks to financial support of the U.S. government for many years has proposed more or less complicated applications, like computer or manipulator, composing of $\mathrm{C}, \mathrm{N}, \mathrm{H}$, and other atoms.

It has been a childhood of nanomaterials and nanotechnologies. Now there is a huge number of research devoted to this subject, e.g. only in Internet one might find $3,440,000$ files on nanomaterials and 2,8880,000 files on nanotechnologies. Even the current achievements are generally still very far from imaginations of Feynman and Drexler, we constantly try to touch them, and present nanomaterials demonstrate such extraordinary mechanical, chemical and physical properties that they become the mostly investigated and developed class of materials.

In this paper the examples of nanomaterials, then specific technologies resulting in their fabrication, and finally the application of nanomaterials limited to structural materials and biomaterials are presented in a very synthetic way. 


\section{NANOMATERIALS}

Nanomaterials have always existed in nature, in human and animals bodies, in flowers and trees, in smog and fog. As to discover the nanoparticles, it has been possible after developing the electron microscopes capable to differentiate the details at nanoscale resolution. The typical case is that of clay minerals, like montmorillonite.

Clay minerals are an important class of nano-sized materials that are used in a number of diverse technological and environmental applications. They have layered structure formed by tetrahedral sheet(s) linked to an octahedral sheet through sharing of apical oxygens. The layer thickness is around $1 \mathrm{~nm}$, and the lateral dimensions of these layers may vary from $30 \mathrm{~nm}$ to several microns or larger, depending on the particular layered silicate. This aspect ratio offers an extremely high surface area and hence a lot of interesting possibilities for modifying clay particles properties [2].

Present nanomaterials proposed to be applied include single elements, mixtures of elements, like metallic alloys, and chemical compounds, like organic and inorganic particles, ceramics including.

Among elements, only one enterprise [3] gives the list of over twenty produced elements of nanometric size: $\mathrm{Al}, \mathrm{Ce}, \mathrm{Co}, \mathrm{Cu}, \mathrm{Au}, \mathrm{In}, \mathrm{Fe}, \mathrm{La}, \mathrm{Mg}, \mathrm{Mo}, \mathrm{Ni}, \mathrm{Nb}, \mathrm{Au}, \mathrm{Ta}$, $\mathrm{Sn}, \mathrm{Ti}, \mathrm{W}, \mathrm{Y}, \mathrm{Zn}, \mathrm{Zr}$. Silicon is developed to use in nanoelectronics [4]. Ge nanocrystals are also investigated for their application in electronics [5]. Carbon nanotubes are wellknown from many years. It might be then said that all known elements forming solids at ambient temperature may be produced if such demands are formulated.

Among inorganic compounds are among others: carbides $\mathrm{B}_{4} \mathrm{C}, \mathrm{Cr}_{3} \mathrm{C}_{2}, \mathrm{Mo}_{2} \mathrm{C}, \mathrm{NbC}, \mathrm{SiC}$, $\mathrm{TaC}, \mathrm{TiC}, \mathrm{VC}, \mathrm{WC}, \mathrm{ZrC}$; nitrides $\mathrm{AlN}, \mathrm{BN}, \mathrm{B}_{3} \mathrm{~N}_{4}, \mathrm{CrN}, \mathrm{GaN}, \mathrm{NbN}, \mathrm{Si}_{3} \mathrm{~N}_{4}, \mathrm{TaN}, \mathrm{TiN}$, VN, WN, ZrN; carbonitrides $\mathrm{Si}_{3}\left(\mathrm{C}_{0.5} \mathrm{~N}_{0.5}\right)_{4}, \mathrm{TiC}_{0.8} \mathrm{~N}_{0.2}, \mathrm{TiC}_{0.7} \mathrm{~N}_{0.3}, \mathrm{TiC}_{0.5} \mathrm{~N}_{0.5}$; borides $\mathrm{CrB}, \mathrm{LaB}_{6}, \mathrm{Mo}_{2} \mathrm{~B}, \mathrm{TiB}, \mathrm{WB}, \mathrm{ZrB}_{2}$; phosphides $\mathrm{GaP}$, InP; sulphides $\mathrm{CaS}, \mathrm{FeS}, \mathrm{MoS}_{2}$, $\mathrm{PbS}, \mathrm{ZnS}$. A lot of oxides is produced: single oxides $\mathrm{Al}_{2} \mathrm{O}_{3}, \mathrm{~B}_{2} \mathrm{O}_{3}, \mathrm{Bi}_{2} \mathrm{O}_{3}, \mathrm{CeO}_{2}, \mathrm{CoO}$, $\mathrm{Co}_{3} \mathrm{O}_{4}, \mathrm{CrO}_{3}, \mathrm{Cr}_{2} \mathrm{O}_{3}, \mathrm{CuO}, \mathrm{Dy}_{2} \mathrm{O}_{3}, \mathrm{Er}_{2} \mathrm{O}_{3}, \mathrm{Eu}_{2} \mathrm{O}_{3}, \mathrm{Fe}_{2} \mathrm{O}_{3}, \mathrm{Fe}_{3} \mathrm{O}_{4}, \mathrm{Gd}_{2} \mathrm{O}_{3}, \mathrm{HfO}_{2}, \mathrm{In}_{2} \mathrm{O}_{3}$, $\mathrm{La}_{2} \mathrm{O}_{3}, \mathrm{MgO}, \mathrm{Mn}_{2} \mathrm{O}_{3}, \mathrm{Mn}_{3} \mathrm{O}_{4}, \mathrm{MoO}_{3}, \mathrm{Nd}_{2} \mathrm{O}_{3}, \mathrm{NiO}, \mathrm{Ni}_{2} \mathrm{O}_{3}, \mathrm{PbO}, \mathrm{Pr}_{6} \mathrm{O}_{11}, \mathrm{Sb}_{2} \mathrm{O}_{3}, \mathrm{SiO}_{2}$, $\mathrm{Sm}_{2} \mathrm{O}_{3}, \mathrm{SnO}_{2}, \mathrm{~Tb}_{4} \mathrm{O}_{7}, \mathrm{TiO}_{2}$ (both anatase and rutile), $\mathrm{VO}, \mathrm{V}_{2} \mathrm{O}_{3}, \mathrm{~V}_{2} \mathrm{O}_{5}, \mathrm{WO}_{3}, \mathrm{Y}_{2} \mathrm{O}_{3}$, $\mathrm{ZnO}, \mathrm{ZrO}_{2}$; multiple oxides $\mathrm{BaCO}_{3}, \mathrm{BaFe}_{12} \mathrm{O}_{19}, \mathrm{BaSO}_{4}, \mathrm{BaTiO}_{3}, \mathrm{CaCO}_{3}, \mathrm{Ca}_{5}\left(\mathrm{PO}_{4}\right) \mathrm{F}$, $\mathrm{CoFe}_{2} \mathrm{O}_{4}, \mathrm{CuFe}_{2} \mathrm{O}_{4}, \mathrm{MgAl}_{2} \mathrm{O}_{4}, \mathrm{MgFe}_{2} \mathrm{O}_{4}, \mathrm{Li}_{4} \mathrm{Ti}_{5} \mathrm{O}_{12}, \mathrm{NiFe}_{2} \mathrm{O}_{4}, \mathrm{In}_{2} \mathrm{O}_{3}: \mathrm{SnO}_{2}, \mathrm{Li}_{2} \mathrm{CO}_{3}$, $\mathrm{LiCoO}_{2}, \quad \mathrm{LiMn}_{2} \mathrm{O}_{4}, \quad \mathrm{SrAl}_{12} \mathrm{O}_{19}, \quad \mathrm{SrAl}_{12} \mathrm{O}_{19}, \quad \mathrm{SrCO}_{3}, \quad \mathrm{SrFe}_{12} \mathrm{O}_{19}, \quad \mathrm{SrTiO}_{3}, \quad \mathrm{Y}_{3} \mathrm{Al}_{5} \mathrm{O}_{12}$, $\mathrm{ZnFe}_{2} \mathrm{O}_{4}$; hydroxides $\mathrm{Al}(\mathrm{OH})_{3}, \operatorname{In}(\mathrm{OH})_{3}, \mathrm{Mg}(\mathrm{OH})_{2}$ [3].

Organic compounds include nanomaterials with tailored structures and functions including dendrimers, supermolecules, artificially-designed proteins, inorganic clusters, polymers, etc. These nanomaterials (nano/organic modules) are used as functional units in new materials in the form of thin films, fibers, and nano-devices. We design nanoarchitectures composed of functional modules to meet specific applications, and aim at the development of new functional bio-polymers, ultra-sensitive detection systems for bio-molecules, and nano-separation membranes indispensable for green chemistry [6].

Nanomaterials may be produced in different forms: as atomic \& molecular clusters, buckyballs \& fullerenes, bulk nanostructured metals, carbon nanohorns / single wall carbon nanohorns (SWNHs), magnetic nanoparticles / magnetic nanostructures, nanobelts, nanocrystals \& nanopowders, nanofillers / nanoadditives, nanoparticles / nanopowders, nanorods, nanosponge abrasives, nanotubes, nanowires, quantum dots / nanodots, etc. [3]. An example illustrates Fig. 1. 
Summarising, there is no problem today to produce almost any nanospecies. The choice depends on nanomaterial demanded and capabilities of a specific method.

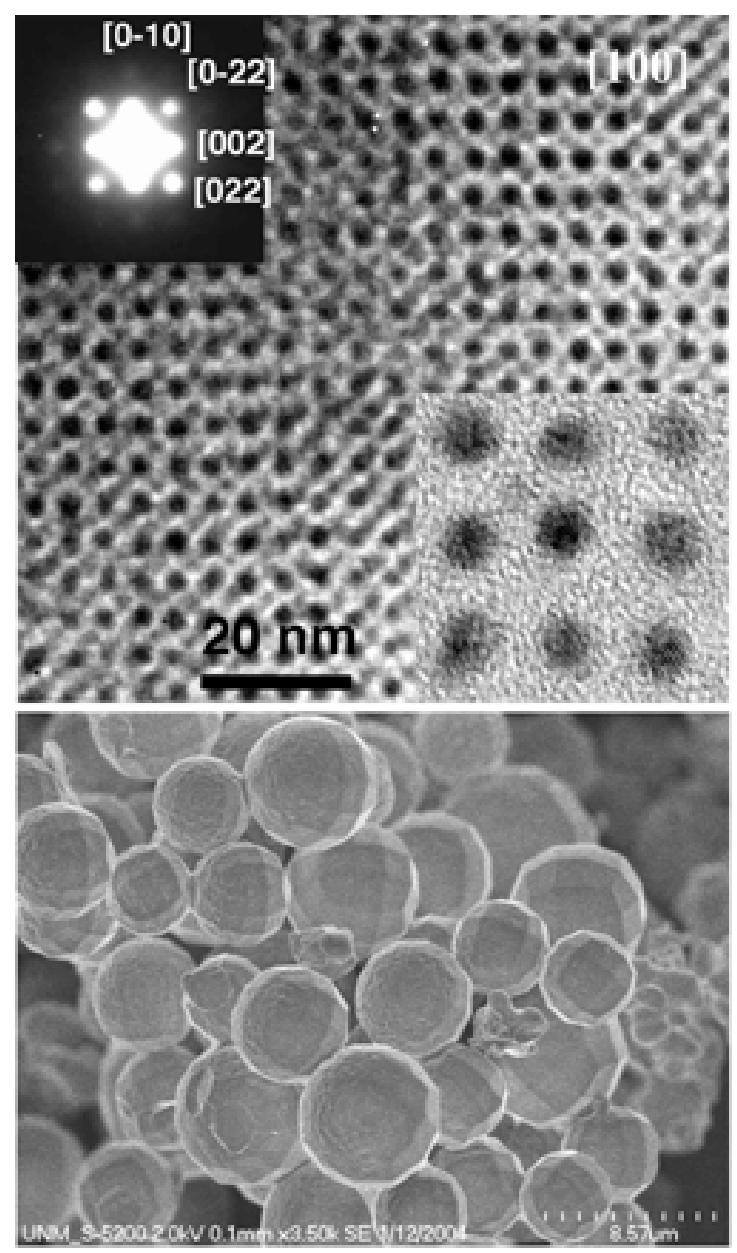

Fig. 1. Top image: ordered gold nanocrystal packed inside silica. Electron diffraction pattern (left corner image) and high-resolution image (right corner) confirmed the nanostructure and gold nanocrystals.

Bottom image: self-assembled, well-shaped gold nanocrystal/silica arrays [7]

\section{NANOTECHNOLOGIES}

The creation of nanomaterials has been reported as generally performed by two different approaches: (i) assembly of atoms into nanostructures (bottom-up) and (ii) transformation of large structure blocks into nanometric grains (top-down). The first approach is often used to obtain electronic and magnetic special materials, biostructures, etc. And second approach is more popular for modification of construction materials as the drastic decrease in grain size is followed by an appearance of the Coble slip along the grain boundaries replacing the dislocation slip, and thus in increasing hardness, strength, wear resistance [8]. Such approach seems too general. There has been proposed five different ways to obtain nanomaterials and nanostructures shown in Fig. 2. 


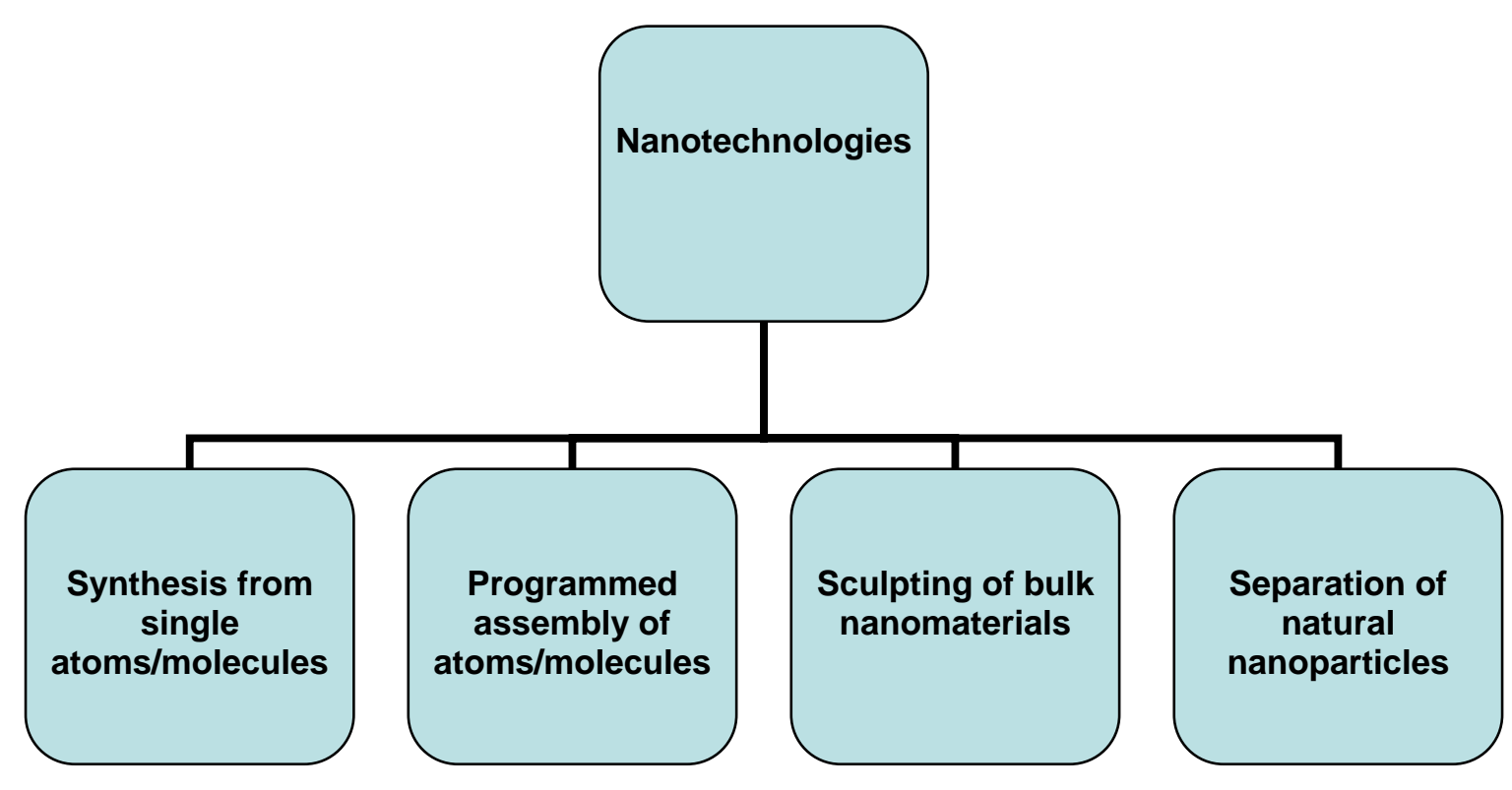

Fig. 2. General types of nanotechnologies

The properties of nanostructures to a great extent depend on fabrication technique. There is a great number of such mechanical, physical and chemical methods developed to obtain nanocrystals. The more recent methods, their applications, advantages and limitations are presented.

\section{Plastic deformation}

Ideas of plastic deformation are based on light or heavy cold deformation resulting in fragmentation of grains. As the best, twisting, torsion, and extrusion methods are declared (Fig. 3). Among cold treated materials are: amorphous $\mathrm{Al}$ alloys, $\mathrm{Cu}$ alloys, titanium $[9,10]$.
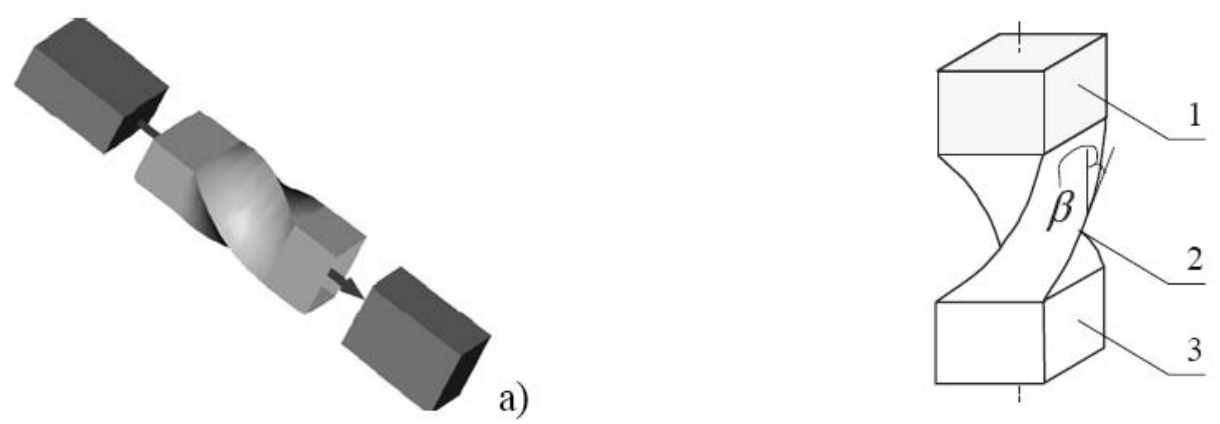

b)

Fig. 3. Schematic illustration showing the principle of Twist Extrusion (TE): (a) passing a sample through the channel and (b) the shape of the twist channel with the input (1), twist (2) and calibrating (3) parts and the twist line angle $\beta$ [9] 


\section{Mechanical attrition}

This group of technologies is aimed at obtaining nanopowders composed of nanoparticles, where particles have an average diameter below $50 \mathrm{~nm}$ [11]. The pressing and milling are very popular. True nanoparticles exist free to move in relationship with each other and accordingly when not in liquid suspension resemble smoke particles. A jar of a true nanopowder when emptied from chest height towards the floor will disperse into the air before reaching the floor. Most manufacturers of "nanopowders" produce micropowder assemblies of nanoparticles but the powder itself is rarely a nanopowder. In the aggregated nanopowder the each individual particle contains a complex chemical compound. Such compounds have two or more different cations (positively charged elements) in their chemical formula. An example of a complex compound is calcium titanate $\left(\mathrm{CaTiO}_{3}\right)$.

\section{Controlled detonation (CDS)}

Controlled Detonation Synthesis is based on super-high pressure developed at explosion in closed volume [12]. At explosion precursor material, immersed in specific gas medium, is atomized. During the fly from the middle of reactor to the reactor walls atoms are clusterized and form nanoparticles. During whole synthesis process the superhigh pressure is supported which enable formation not only different nanoceramics with unusual crystalline lattice, but also of cubic carbon nanoparticles (nanodiamonds).

\section{Hot Plasma Jet Synthesis (HPJS)}

In the hot plasma process [12] the precursor material is atomized in plasma arc with followed clusterization to nanoparticles optionally with additional plasma chemical conversion to another material than precursor. The special precautions are taken to get real nanocrystals (not simply mixed phases) and to exclude big agglomerate formation.

\section{Laser vaporization}

An example of the capacities of this technique, laser vaporization by ablating at a solid target in the vapour phase, has been developed to produce encapsulated titanium nanocrystals [13]. By vaporizing sponge titanium in benzene vapour, the single titanium crystals encapsulated in carbon nanocages have been synthesized in good yields. The sizes of the encapsulated crystals are around $5-15 \mathrm{~nm}$ and the numbers of the wrapped graphitic layers are of the order of 3-10 layers. Another example is growth of carbon nanostructure materials [14].

\section{Plasma vapour deposition (PVD) and chemical vapour deposition (CVD) methods}

Nanoparticles or nanorods can grow by different PVD methods, like radio frequency (RF) or direct current (DC) magnetron sputtering, e.g. Si, Cu, GaAs [15-17]. Surface area is increased substantially for such composite nanostructures. 
The CVD method is widely used for nucleation and growth of Si nanocrystals on dielectric surfaces [18].

\section{Ultrasonic irradiation}

Recently the possibility to obtain CdS nanocrystals by ultrasonic irradiation in microemulsion was reported [19].

\section{Milling and annealing methods}

The combination of both techniques is utilized for producing the carbon or BN nanotubes as shown in Fig. 4 [20,21]. The BN nanotubes with a diameter less than 10 $\mathrm{nm}$ and a well-crystallized multiwalled structure were formed via an in situ nitriding reaction. The formation of the unique multiwalled structure was attributed by a twodimensional growth of the BN phase and a nonmetal catalytic growth [20].
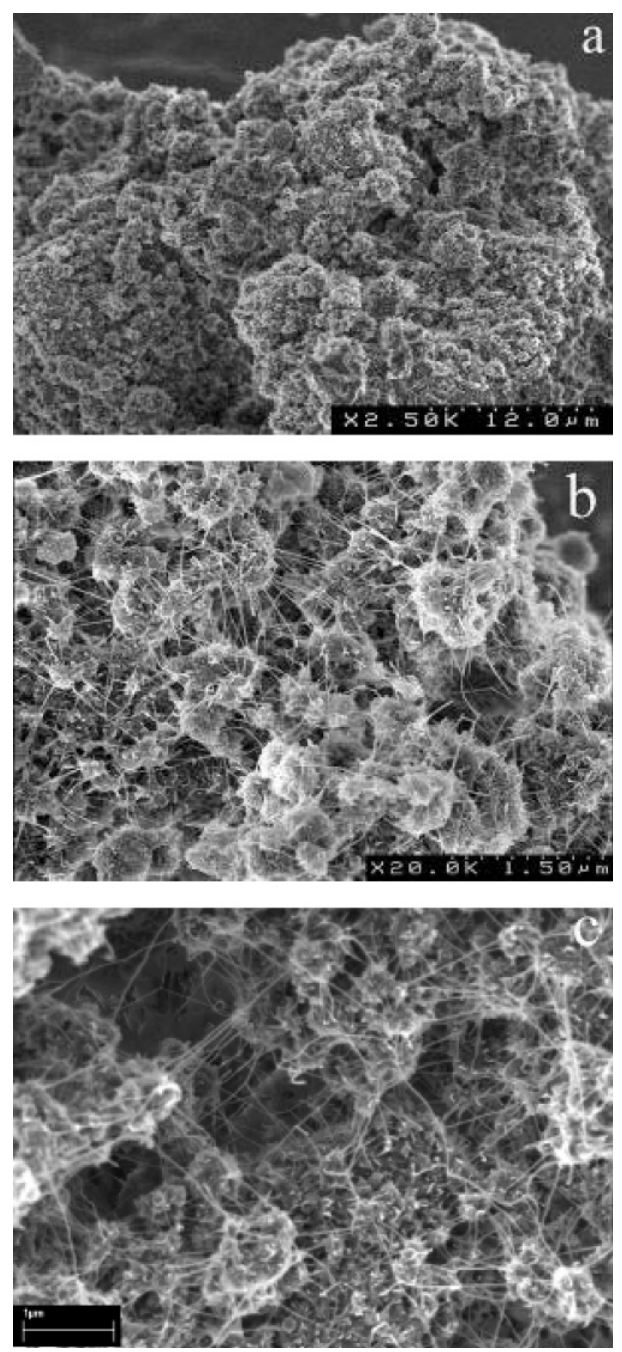

Fig. 4. SEM images taken at different magnifications after first ball milling for $150 \mathrm{~h}$ and subsequent annealing at $1200^{\circ} \mathrm{C}$ for $8 \mathrm{~h}$ in $\mathrm{NH}_{3}[20]$ 


\section{Nanoimprint lithography}

Lithography is usually the first step in producing the microchips. The light is shone through a stencil onto a silicon wafer that is coated with a light-sensitive polymer. The next step, chemical etching removes the regions of silicon coated with either the unexposed or the exposed polymer, until the desired structure is achieved. Finally, the remaining polymer is washed off. The components on a microchip are made by carving patterns into layers of doped and undoped silicon. Recently, Chou et al. [22] imprinted patterns onto silicon using quartz moulds with a resolution of just $10 \mathrm{~nm}$ and an 'imprint time' of $250 \mathrm{~ns}$, which is the important achievement in nanotechnology of semiconductors.

\section{Electrocrystallization}

Electrocrystallization has been developed in order to obtain highly complex nanostructures [23]. As an example, the fabrication of CoNi cylinders by nanolithography followed by electrodeposition for magnetic registration media can be given [24].

\section{Anodization}

Anodization is another electrochemical approach used to fabricate complex surface nanolayers, e.g. nanotubes of $\mathrm{Ti}$ oxides [25], amorphous films with embedded silicon nanocrystals by anodization of bulk crystalline $\mathrm{Si}$ [26]. Porous $\mathrm{SiC}$ films were fabricated by electrochemical anodization of $\mathrm{SiC}$ wafers and SiGe [27], thin alumina films on a silicon substrate by anodization in a weak acid [28].

\section{Annealing}

Simple annealing may result in very complex nanostructures. Examples are given in Ferromagnetic cobalt nanocrystals obtained by soft annealing [29] and $\mathrm{Si}$ and $\mathrm{Ge}$ nanocrystals [30].
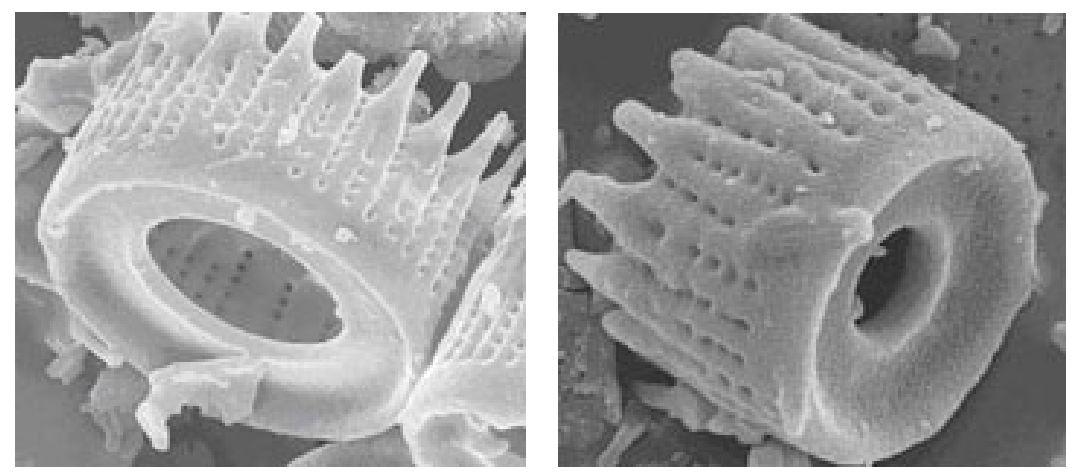

Fig. 5. Silica diatom (on left) and diatom converted to MgO [31] 
In Fig. 5 the example of conversion of the silica-based diatom nanostructures to materials such as $\mathrm{MgO}$, while preserving their complex shapes, is shown [31]. Diatoms are single-celled aquatic microorganisms, which assemble complex silica microshells (frustules) containing channels, pores or other intricate features. Although the sizes of diatoms vary, typical frustule dimensions are around 100 micrometers. Such 3D assemblies of magnesia nanocrystals could have agricultural, pharmaceutical, petrochemical, environmental and structural applications.

\section{Sol-gel methods}

These are methods which are relatively cheap and possessing many advantages. They are able to produce materials (both metals and ceramics) at ultra-low temperatures, in large quantities, synthesize almost any material or co-synthesize two or more materials simultaneously, coat one or more materials onto other materials (metal or ceramic particulates, and three-dimensional objects), produce extremely homogeneous alloys, synthesize ultra-high purity $(99.9999 \%)$ materials, tailor the composition very accurately even in the early stages of the process, because the synthesis is actually performed on an atomic level, precisely control the microstructure of the final products, and precisely control the physical, mechanical, and chemical properties of the final products.
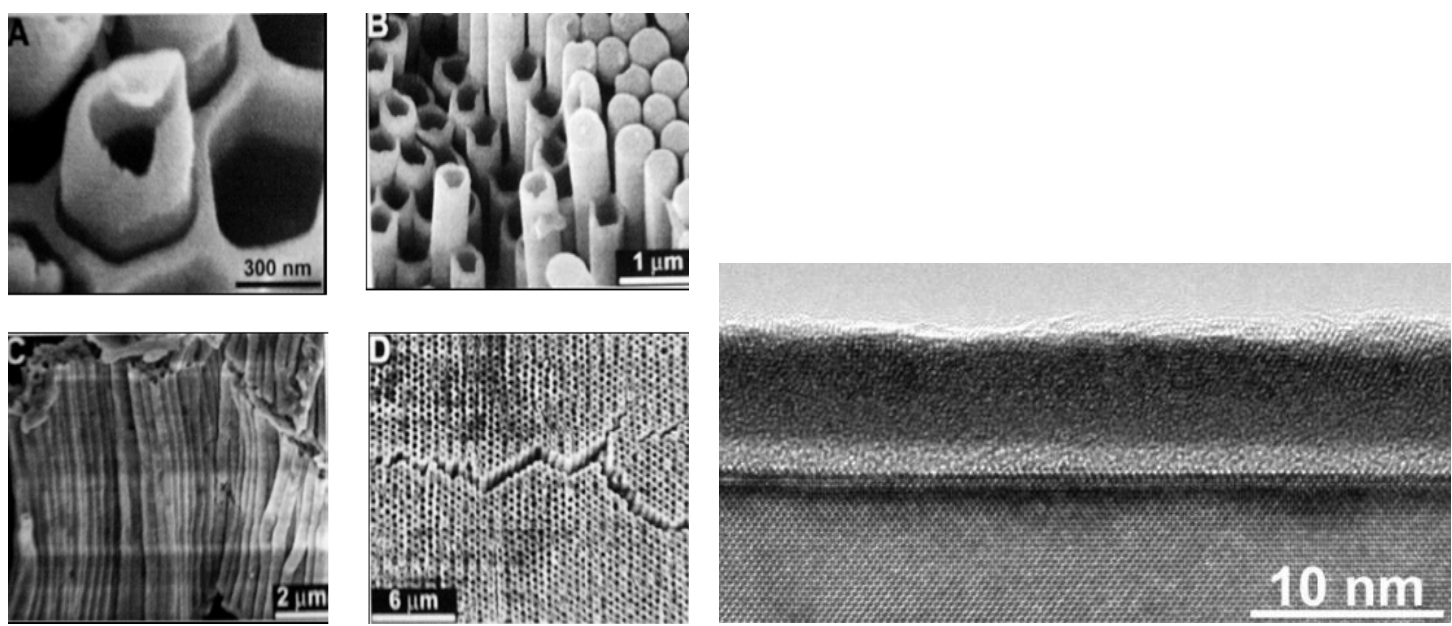

Fig. 6. Examples of applications of sol-gel technique: Polymer nanotubes, longer than $100 \mu \mathrm{m}$ and pores diameter between 300 and $900 \mathrm{~nm}$ (left, A, B, C and D ([32]) and TEM image of a $5 \mathrm{~nm} \mathrm{Nd} \mathrm{O}_{3}$ layer deposited by water-based chemical-solution deposition [33]

Sol-gel techniques make possible to obtain not only very thin film coatings but xerogels and aerosols [34].

\section{Electrospinning}

It is the most efficient technique used to obtain fibres of a few nanometers in thickness, applied for various boron, carbon and metal fibre reinforced composites. 

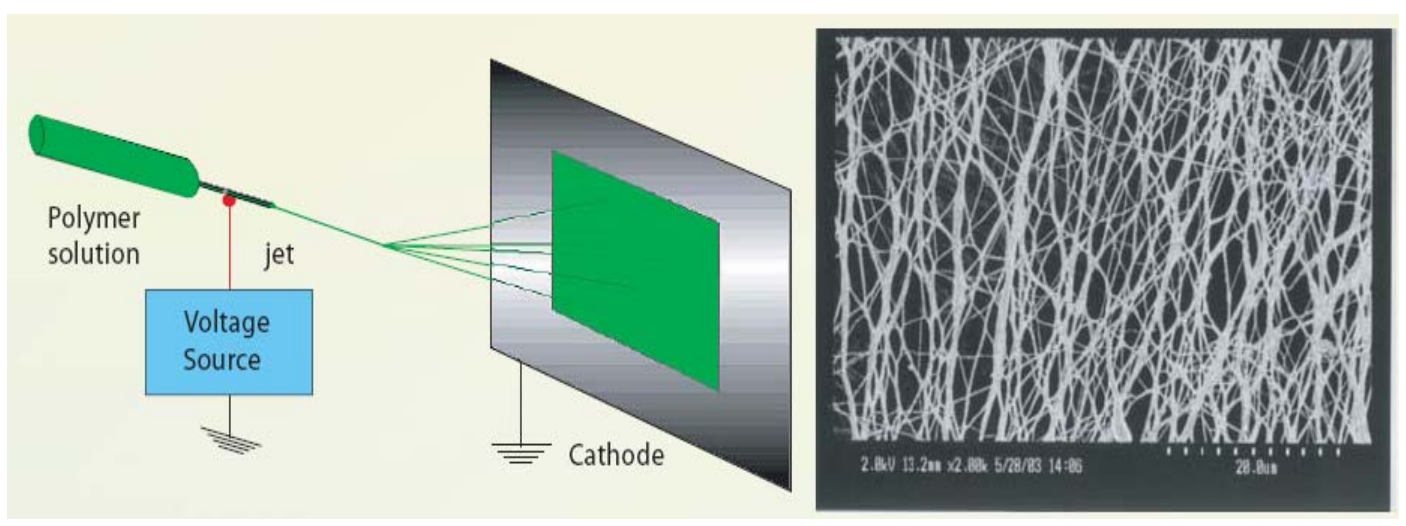

Fig. 7. Nanofibers achieved by electrospinning [35]

\section{Laser melting followed by rapid cooling}

The idea of this surface modification is performed by two different techniques. The first relies on melting of the surface with short pulse laser and subsequent cooling in air. Another approach composes of melting with high power $\mathrm{CO}_{2}$ laser of the specimen maintained in liquid nitrogen. The obtained results show that in a such way the relatively thick nano grain layer appears on the Al-Si [36] and $\mathrm{Cu}-\mathrm{Sn}$ alloys.

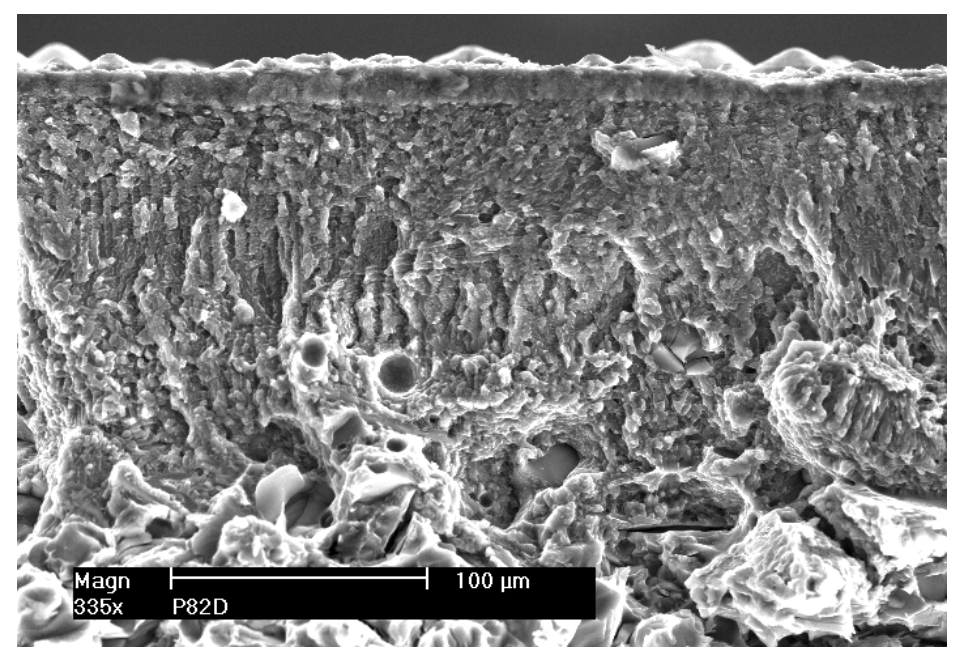

Fig. 8. Cross-section of the surface melted Al-Si alloy [36]. Thick remelted layer with thin top zone is seen

\section{Hydrogen induced amorphisation}

The technique is based on earlier discovery that some refractory metals and their alloys, especially titanium, undergo hydrogen-induced martensitic transformation resulting in nanometric grain structure [37] as shown in Fig. 9. 

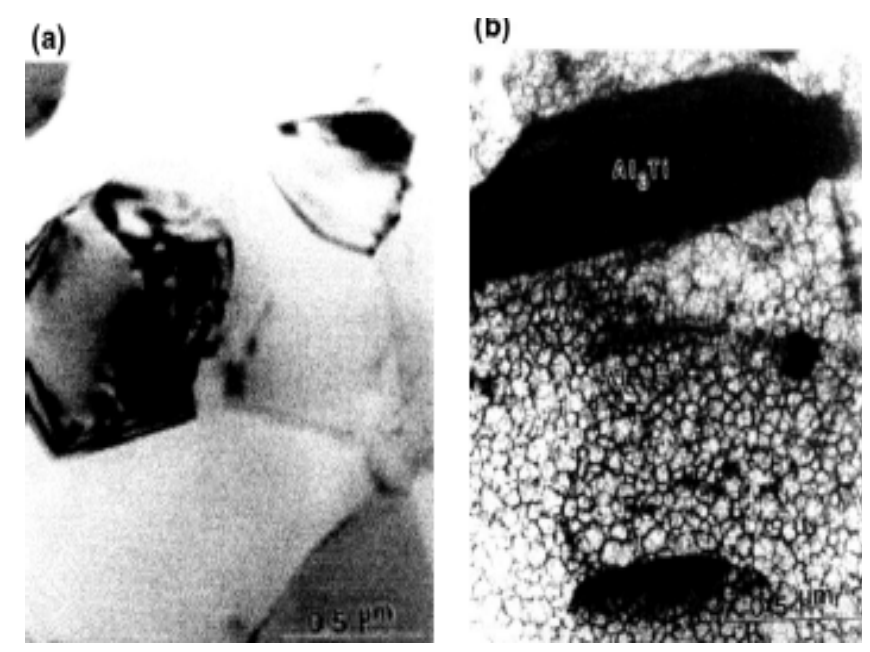

Fig. 9. Microstructure of titanium before (on left) and after (on right) hydrogen-induced transformation [37]

\section{APPLICATIONS}

Considering both structural and functional materials, the greatest achievements in research and development may be noted for only some structural materials, nanocoatings, electronic materials, in energetics (nanoceramics), chemical sensors, etc., and wide variety of biomedicine branches, including first of all regenerative medicine, cancer therapy, pharmacology, cosmetics industry.

The nanocrystallised structural materials are difficult to obtain. Therefore, the application of heavily deformed titanium, copper, etc. has not been widely developed yet.

The promising direction of research and application is a creation of nanocrystalline layers on normally ductile materials. Such layers have been successfully obtained by laser evaporation and cooling in cryogenic conditions [36]. Some future projects suggest that the nanocrystalline layers could be obtained by a variety of techniques: hydrogen-induced amorphisation of Ti alloys [37], surface melting with an excimer laser in air [38-40], mechanical pulse treatment [41], likely surface plasma melting in liquids.

The nanocoatings can be used as thermal barrier materials. The fruitful solution has been an application of nano $\mathrm{ZnO}$ [43] and $\mathrm{TiO}_{2}$ [42] for producing the transparent barriers put on glass to prevent UV radiation and the adhesion of water, oils and greases.

The nanomaterials can bring a great advancement in a few branches of medicine. The first field is implants and prosthetics [44]. It could be possible to create artificial organs and implants that are more akin to the original, through cell growth on artificial scaffolds or biosynthetic coatings that increase biocompatibility and reduce rejection. These could include retinal, cochlear and neural implants, repair of damaged nerve cells, and replacements of damaged skin, tissue or bone [45]. An example is a proposal to chemically treat the titanium and subject it to anodization. The last process creates a pitted coating in the surface of the titanium. Now, those pits are packed with a cobalt catalyst and then the titanium goes through a chemical process that involves heating them to a scorching $700^{\circ} \mathrm{C}$. That causes carbon nanotubes to sprout from each pit. It 
has been observed that after three weeks the bone cells grew twice as fast on the titanium covered in nanotubes. Cells interacting with the nanotubes also made significantly more calcium - the essential ingredient for healthy bones [46].

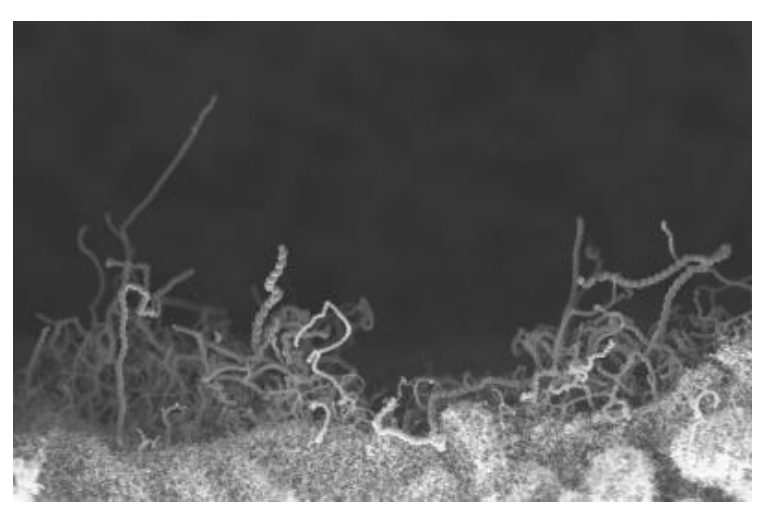

Fig. 10. Carbon nanotubes on titanium surface [46]

The interesting application lies in cancer diagnosis and therapy. A new fabrication technique [47] allows the control over the structure and function of drug delivery nanoparticles. Called PRINT (Particle Replication In Non-wetting Templates), the technique is similar to injection molding and uses principles borrowed from the electronics industry for transistor fabrication.

The manufacturing process starts with a silicon wafer that is etched with the shape and size of the desired nanoparticle, resulting in a template. Next, nonstick liquid fluoropolymers are poured into the template and cured to form a fixed mold. The finished mold is then injected with organic materials that can contain imaging agents, anticancer drugs, DNA (for gene therapy) and other materials, depending on the intended function. The resulting nanoparticles can be as small as 20 nanometers, or thousands of times smaller than the width of a single human hair. The shapes of the particles can also be made to mimic the shapes of objects found in nature like red blood cells or virus particles.

Another approach focuses on an use of ferromagnetic nanoparticles of iron oxides. Strong adverse effects on the healthy tissue in the vicinity of a tumour are a major drawback in current cancer therapies. One innovative technological approach to solve this problem focuses on therapies at the cellular level by applying intracellular probes, i.e. the transfer of nano-sized biocompatible devices into the cells. These devices (particles) must meet the demands of targeted investigation of relevant cell parameters as well as manipulation of the cells. When the transferred nanoparticles exhibit ferromagnetic properties, external magnetic fields can be used for manipulation in deep layers of (human) tissue since they provide a unique way to penetrate tissue noninvasively and without known adverse effects. External static magnetic fields fix the ferromagnetic nanoparticles at a precise position; gradient fields move them and alternating (AC) fields lead to local heating. The latter can be utilized for so-called "hyperthermia", i.e. a therapeutic anti-cancer treatment to raise the temperature of tumor tissue in-vivo. This method applies the fact that a cancer cell-killing effect is caused when a temperature above $41-42^{\circ} \mathrm{C}$ is maintained in the target volume $[48,49]$. Biomolecules coated ultra small superparamagnetic iron oxide (USPIO) particles injected in the blood stream recognize target molecular markers present inside cells and induce a specific signal for detection by magnetic resonance imaging (MRI). This 
technology may allow for detection of individual cancer cells months or years earlier than traditional diagnostic tools, which require the presence of hundreds of cancer cells [50].

Nanotechnology methods can improve medical diagnostics. Early detection of disease remains a primary goal of the medical community. Nanotechnology holds great promise for enabling the achievement of this goal. Nanoparticles in particular have exhibited tremendous potential for detecting fragments of viruses, pre-cancerous cells, disease markers, and indicators of radiation damage. Gold coatings have made it possible to use toxic cobalt nanoparticles for biomedical applications. Gold coated ferromagnetic nanoparticles tagged with HIV antibodies may be able to detect virus particles left after completion of conventional drug therapy. Metal nanoparticles forming dendrimers have also been functionalized with different biomolecules to detect specific proteins, antibodies, and other disease indicators. Fluorescent markers can also be attached to the dendrimers [50].

The drug delivery remains one of the most important applications of nanomaterials. Two promising approaches include an use of nanoporous or soft materials. The representative hydrophobic anticancer drug camptothecin has been proposed to put into the pores of fluorescent mesoporous silica nanoparticles delivering the particles into a variety of human cancer cells to induce cell death. Camptothecin CPT and its derivatives are considered to be among the most effective anticancer drugs of the $21 \mathrm{st}$ century. Although studies have demonstrated their effectiveness against carcinomas of the stomach, colon, neck and bladder, as well as against breast cancer, small-cell lung cancer and leukemia in vitro, clinical application of CPT in humans has only been carried out with CPT derivatives that have improved water solubility. To overcome these problems, drug delivery systems using pegylated polymers, liposomal particles or albumin-based nanoparticles have been developed.

New results suggest that the mesoporous silica nanoparticles might be used as a vehicle to overcome the insolubility problem of many anticancer drugs [51].

Design and development of different forms of soft matter from renewable (biomass) feedstocks is gaining attention in current research. In [52] cashew nut shell liquid, an industrial by-product, was used as a raw material to synthesize aryl glycolipids which upon self-assembly generated an array of soft materials such as lipid nanotubes, twisted/helical nanofibers, low-molecular-weight hydro/organogels and liquid crystals. In another example, amygdalin, a by-product of the apricot industry, was used to develop novel amphiphiles, which showed unprecedented gelation properties in a wide range of solvents. These soft nanomaterials successfully demonstrated their utility as hydrogels for drug delivery vehicles. The enzyme catalysis was used as a tool to make and break the hydrogels, which apparently triggered controlled drug delivery.

\section{SUMMARY}

A number of different methods are proposed to obtain nanometric powders, fibres, bulk materials, their surface layers and coatings. These methods are very specific and decide on potential applications. The progress in application of nanomaterials and nanostructures seems the most substantial in medicine, sport and military industry because of high production costs and some exciting promises. 


\section{REFERENCES}

1. The Encyclopedia of Nanoscience and Nanotechnology. H.S. Nalwa [ed.], USA, 2004.

2. hhttp://www.uach.sav.sk/web/dokumenty/APVV/APVV_050505_ENG.pdf

3. http://www.mknano.com/?gclid=CLuJ4_qevo8CFQ6ZQwodTynEYA

4. http://spore.cta.int/spore124/spore124_feature.asp

5. Yang H., Yang R., Wan X., Wan W.: Structure and photoluminescence of Ge nanoparticles with different sizes embedded in $\mathrm{SiO}_{2}$ glasses fabricated by a sol-gel method. J. Crystal Growth 261 (2004) 549-556.

6. http://www.nims.go.jp/onc/index_e.html

7. http://www.sandia.gov/news/resources/releases/2004/micro-nano/nanotoolcase.html+

8. Pande C.S., Masumura R.A.: Deformation and Coble creep of nanocrystalline materials. Mat. Res. Soc. Symp. Proc., Vol. 740, 2003, chpt. 11.1.

9. Varyukhin V.M., Tkatch V.I., Maslow V.V., Beygelzimer Y.Y., Synkov S.G., Nosenko V.K., Rassolov S.G., Synkov A.S., Krysov V.I., Mashira V.A.: Consolidation of amorphous $\mathrm{Al}_{86} \mathrm{Ni}_{6} \mathrm{Co}_{2} \mathrm{Gd}_{6}$ melt-spun ribbons by twist extrusion. Mater. Sci. Forum 503504 (2006) 699-704.

10. Stolyarov V.V., Zhu Y.T., Lowe T.C., Valiev R.Z.: Microstructures and properties of ultrafine-grained pure titanium processed by equal-channel angular pressing and cold deformation. J. Nanosci. Nanotechn. 1 (2001) 237-242.

11. De Castro C.L., Mitchell B.S.: Synthesis, Functionalization and Surface Treatment of Nanoparticles. M.I. Baraton (ed.). Amer. Sci. Publ., 2002, pp. 11-15.

12. http://www.plasmachem.com/contentenglish/nanopowders_technology.html

13. Chen H., Huang R.B., Tao Z.C., Zheng L.-S., Zhou G.-W., Zhang Z.: Single titanium crystals encapsulated in carbon nanocages obtained by laser vaporization of sponge titanium in benzene vapor. Appl. Phys. Lett. 77 (2000) 91-93.

14. Zhu S., Su C.-H., Cochrane J.C., Lehoczky S., Muntele I., Ila D.: Growth of carbon nanostructure materials using laser vaporization. Diamond Related Mater. 10 (2001) 11901194.

15. Roca i Cabarrocas Nguyen-Tran Th., Djeridane Y., Abramov A., Johnson E., Patriarche G.: Synthesis of silicon nanocrystals in silane plasmas for nanoelectronics and large area electronic devices. J. Phys. D: Appl. Phys. 490 (2007) 2258-2266.

16. Kurisu H., Nagoya K., Yamada N., Yamamoto S., Matsuura M.: Characterization of $\mathrm{CuCl}$ nanocrystals in $\mathrm{SiO} 2$ matrix fabricated by inductively coupled plasma-assisted sputtering deposition. J. Vac. Sci. Techn. B 21 (2003) 2169-2173.

17. Vilcarromero J., Bustamante R., da Silva J.H.D.: Hydrogen influence on gallium arsenide thin films prepared by RF magnetron sputtering technique. Brazilian J. Phys. 36 (2006) 1035-1037.

18. Madhukar S., Smith K. et al.: CVD growth of Si nanocrystals on dielectric surfaces for nanocrystal floating gate memory application. http://www.mrs.org/s_mrs/sec_subscribe.asp?CID=2390\&DID=136676\&action=detail

19. Huang J., Xie Y., Li B., Liu Y., Lu J., Qian I.: Ultrasound-induced formation of CdS nanostructures in oil-in-water microemulsions. J. Colloid Interface Sci. 236 (2001) 382384. 
20. Yu J., Chen Y., Wuhrer R., Liu Z., Ringer S.P.: In situ formation of BN nanotubes during nitriding reactions. Chem. Mater. 17 (2005) 5172-5176.

21. Gao B., Bower C., Lorentzen J.D., Fleming L., Kleinhammes A., Tang X.P., McNeil L.E., $\mathrm{Wu}$ Y., Zhou O.: Enhanced saturation lithium composition in ball-milled single-walled carbon nanotubes. Chem. Phys. Lett. 327 (2000) 69-75.

22. Chou S.Y., Keimel C., Gu J. : Ultrafast and direct imprint of nanostructures in silicon. Nature 417 (2002) 835-837.

23. Staikov G., Milchev A.: The Impact of Electrocrystallization on Nanotechnology. Pages 129. Wiley 2007.

24. Ross A., Hwang M., Shima M.: Micromagnetic behaviour of electrodeposited cylinder arrays. Phys. Rev. B 65 (2002) 14-17.

25. Macak J.M., Albu S., Kim D.H., Paramasivam I., Aldabergerova S., Schmuki P.: Miltulayer $\mathrm{TiO}_{2}$-nanotube formation by two-step anodization. Electrochem. Solid-State Lett. 10 (2007) K28-K31.

26. Gardelis S., Tsiaoussis I., Frangis N., Nassiopolou A.G. : Ultra-thin films with embedded $\mathrm{Si}$ nanocrystals fabricated by electrochemical dissolution of bulk crystalline $\mathrm{Si}$ in the transition regime between porosification and electropolishing. Nanotechnology 18 (2007) 115705. http://www.iop.org/EJ/abstract/0957-4484/18/11/115705.

27. Kartopu G., Ekinci Y.: Further evidence on the observation of compositional fluctuation in silicon-germanium alloy nanocrystals prepared in anodized porous silicon-germanium films. Thin Solid Films 473 (2005) 213-217.

28. Kokonou M., Nassiopolou A.G., Giannakopolous K.P.: Arrays of $\mathrm{SiO}_{2}$ nanoislands grown electrochemically on silicon through nanoporous anodic alumina template. www.isnm2005.org/.../pdf\&filename=paper\%2053\%20(Maria\%20Kokonou).pdf -

29. Petit C., Wang Z.L., Pileni M.P.: Ferromagnetic cobalt nanocrystals achieved by soft annealing approach - From individual behaviour mesoscopic organised properties. J. Magnet. Magnet. Mater. 312 (2007) 390-399.

30. Kachurin G.A., Yanovskaya S.G., Ryuault M.O., Gutakovskii A.K., Zhuravlev K.S. Kaitasov O., Bernas H.: The influence of irradiation and subsequent annealing on $\mathrm{Si}$ nanocrystals formed in $\mathrm{SiO}_{2}$ layers. Semiconduct. 34 (2000) 965-970.

31. http://www.panalytical.com/index.cfm?pid=866

32. Vida-Simiti I., Jumate N., Chicinas I., Batin G.: Applications of scanning electron microscopy (SEM) in nanotechnology and nanoscience. Rom. J. Phys., 49, 9-10 (2004) 955-965.

33. http://www.imec.be/wwwinter/mediacenter/en/SR2006/681619.html

34. http://www.ndhu.edu.tw/ nano/file/chem31300/NT06-L2-Mar07-Nanomaterials.pdf

35. http://www.ntrc.itri.org.tw/research/pdf-2004/08-3.pdf

36. Serbiński W., Zieliński A., Wierzchon T.: Laser assisted forming of the surface layer of Al-Si alloy at cryogenic conditions. Inż. Mater. 25 (2004) 656-658.

37. Eliaz N., Eliezer D., Olson D.L.: Hydrogen-assisted processing of materials. Mater. Sci. Eng. A289 (2000) 41-53.

38. T.M. Yue, T.M. Cheung, H.C. Man, The effects of laser surface treatment on the corrosion properties of Ti-6Al-4V alloy in Hank`s solution. J. Mater. Sci. Lett. 19 (2000) 205-208.

39. T.M. Yue, J.K. Yu, Z. Mei, H.C. Man, Excimer laser surface treatment of Ti-6Al-4V alloy for corrosion resistance enhancement. Mater. Lett. 52 (2002) 206-212. 
40. F. Guillemot, E. Prima et al., Ultraviolet laser surface treatment fore biomedical applications of $\beta$ titanium alloys: morphological and structural characterization, Appl. Phys. A 77 (2003) 899-904.

41. Kyryliv V., Bassarab A., Yaskiv O., Koval J., Voloshyn V., Influence of mechanical pulse treatment on the mechanical and corrosion characteristics of VT-5 alloy. Mater. Sci. 38, 2002,750 .

42. Spanhel L.: Colloidal $\mathrm{ZnO}$ nanostructures and functional coatings: A survey. J. Sol-Gel Sci. Techn. 39 (2006) 7-24.

43. http://www.physorg.com/news10609.html

44. http://www.medicaldevice-network.com/features/feature1061/

45. Wood S., Jones R. Geldart A.: ESRC The Social and Economic Challenges of Nanotechnology report, July 2003. http://www.azonano.com/details.asp?ArticleID=1056

46. Sirivisoot S., Yao C., Xiao X., Sheldon B.W., Webster T.J.: Greater osteoblast functions on multiwalled carbon nanotubes grown from anodized nanotubular titanium for $\begin{array}{llllll}\text { orthopedic applications. } & \text { Nanotechnol. } 18 & \text { (2007) } 365102 & \text { (6pp). }\end{array}$ http://www.iop.org/EJ/abstract/0957-4484/18/36/365102

47. http://www.physorg.com/news12131.html

48. Kumar S.: Nanomaterials for cancer therapy (Nanotechnologies for the life sciences, Vol. 7). Wiley, 2006.

49. http://www.ifw-dresden.de/institutes/iff/research/Carbon/CNT/biomed

50. Medical and Pharmaceutical Applications for Nanomaterials and Nanoparticles - Supplier Data by Strem Chemicals. http://www.azonano.com/details.asp?ArticleID=1336

51. New drug-delivery system using nanomaterials. Medic. Sci. News. http://www.newsmedical.net/?id=26189

52. John G., Vemula P.K.: Design and development of soft nanomaterials from biobased amphiphiles. Soft Matter 2006 (2) 909-914. 